
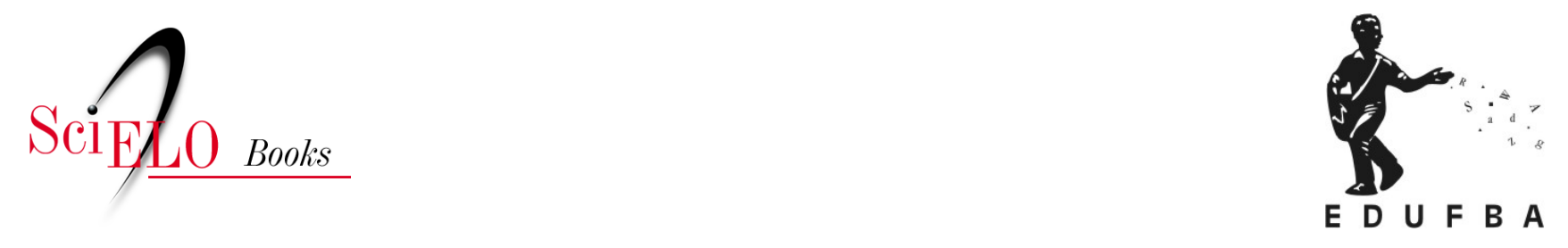

\title{
Mudanças na tabela SIA/SUS e procedimentos coletivos
}

\author{
Thais Regis Aranha Rossi
}

\section{SciELO Books / SciELO Livros / SciELO Libros}

ROSSI, T.R.A. Mudanças na tabela SIA/SUS e procedimentos coletivos. In: Produção social das políticas de saúde bucal no Brasil [online]. Salvador: EDUFBA, 2018, pp. 111-121. ISBN 978-85-2322022-8. https://doi.org/10.7476/9788523220228.0006.

All the contents of this work, except where otherwise noted, is licensed under a Creative Commons Attribution 4.0 International license.

Todo o conteúdo deste trabalho, exceto quando houver ressalva, é publicado sob a licença Creative Commons Atribição 4.0. 


\section{MUDANÇAS NA TABELA SIA/SUS E PROCEDIMENTOS COLETIVOS}

O plano quinquenal de saúde 1990-1995, divulgado no governo Collor, continha metas discretas para a saúde bucal voltadas apenas para o câncer de orofaringe, cárie e doença periodontal. Para o câncer de orofaringe, as ações se voltavam para a capacitação de recursos humanos, aquisição de equipamentos para as unidades de referência e ações de educação em saúde. Quanto à cárie e doença periodontal, para as metas de redução dos índices da doença cárie, foram planejadas as atividades de fluoretação de $100 \%$ das águas de abastecimento público, a garantia de fluoretos tópicos e práticas de higiene oral para todas as crianças em idade escolar, equipar ou reequipar os serviços odontológicos da rede pública, promover o estudo da fluoretação do sal humano, até 31 de dezembro de 1990.

No início da década de 1990, continuaram a ser firmados convênios entre a DNSB e os estados, ainda na gestão de Vitor Gomes Pinto, ${ }^{48}$ a exemplo dos convênios com os estados de Minas Gerais e Paraná. O convênio ${ }^{49}$ celebrado com a Companhia de Abastecimento de Minas Gerais visava a fluoretação dos sistemas de abastecimento de água para redução da cárie dentária, publicado no Diário Oficial da União, de 10 de janeiro de 1990. (BRASIL, 1990c) Já o Termo que tinha como objetivo reduzir os níveis da incidência de cárie dental da população do estado do Paraná foi celebrado com a Secretaria Estadual de Saúde daquele estado (BRASIL, 1990d), publicado em 1 de fevereiro de 1990, no Diário Oficial da União (DOU).

Alguns meses após, foi publicada a exoneração de Vitor Gomes Pinto, em 7 de maio de 1990 (BRASIL, 1990b), no Diário Oficial da União, pelas razões já explici-

48 Vitor Gomes Pinto graduou-se em Odontologia, em 1965, pela UFRGS, fez especialização em Saúde Pública (1973) na USP, mestrado (1977) e doutorado (1992) em Saúde Pública pela USP. Foi técnico do IPEA e diretor da DNSB do Ministério da Saúde, de 1989 a 1990.

Proc. MS/Da n²5000.011825/89. 
tadas no capítulo anterior. Em seu lugar, foi designado, interinamente, na DNSB, o dentista Mércio de Azevedo Ferreira, ${ }^{50}$ participante do GT-Odonto do Ministério da Saúde e integrante enquanto técnico da DNSB. Sérgio de Carvalho Weyne ${ }^{51}$ era amigo da família Collor e foi convidado pela mãe do ex-presidente para exercer o cargo de diretor da DNSB.

Assim, Weyne foi nomeado chefe de Divisão através da Portaria Ministerial $n^{0}$ 555, de 3 de maio de 1990. Um colega de profissão que assessorava Sérgio Weyne considerou sua habilidade e articulação política assim como o cenário político de grandes limitações para o setor saúde.

Os rearranjos no campo burocrático envolveram a criação de dois grupos técnicos no interior da DNSB, um de "Promoção e Prevenção em Saúde Bucal" e outro sobre “Organização de Serviços em Saúde Bucal”. (CARVALHO et al., 2009)

O grupo de Organização dos Serviços de Saúde atuou na formulação da resposta do Estado através dos Procedimentos Coletivos (PC), tendo sido composta por dentistas com experiência na gestão de saúde bucal: Djalmo Sanzi Souza, ${ }^{52}$ do Rio Grande do Sul, José Paulo Gouveia de Toledo, ${ }^{53}$ de São Paulo e Sylvio Gevaerd, ${ }^{54}$ do Paraná. (CARVALHO et al., 2009; WEYNE, 1999) Rui Oppermann, presidente da Aboprev na gestão de 1991 a 1993 e Jaime Aparecido Cury, diretor da referida Associação, também prestaram assessoria à DNSB no período. Benedito Elias Waquim e Mércio de Azevedo Ferreira continuaram como técnicos da DNSB. (WEYNE, 1999)

Assim, dois dentistas que compuseram a nova gestão haviam participado do Comitê Técnico Científico conformado no final da década de 1980, vinculados à Aboprev, além de Djalmo Souza, que havia participado como coordenador de macrorregião na política anterior e nesta se tornava consultor. Outros profissionais eram vinculados à gestão estadual e municipal de saúde bucal com participação no

50 Mércio de Azevedo Ferreira era cirurgião dentista concursado pelo Ministério da Saúde, integrou o GT-Odonto e a Divisão Nacional de Saúde Bucal como técnico, tendo assumido a gestão em alguns momentos.

51 Sérgio de Carvalho Weyne é cirurgião-dentista, formado em 1961, pela UFF. Microbiologista, ele fez especialização em Bioquímica, em 1966, pela mesma, especialização em Odontologia Preventiva, em 1975, pela Indiana University/USA e doutorado em Clínica Odontológica pela Universidade Federal do Rio de Janeiro (UFRJ), em 2004. Professor da UFF, de 1964 a 1992. Foi diretor da Aboprev, de 1995 a 1997.

52 Djalmo Sanzi Souza possui graduação em Odontologia (1971) e especialização em Odontologia Preventiva e Social (1979), ambas pela UFRGS, e mestrado em Saúde Coletiva (2003) pela Universidade Luterana do Brasil (ULBRA). Foi coordenador de saúde bucal da SES do Rio Grande do Sul.

53 Luiz Paulo Gouveia de Toledo é cirurgião dentista, integrou a coordenação nacional do MBRO, de janeiro a julho de 1989, foi coordenador de Saúde Bucal do estado de São Paulo.

54 Sylvio Gevaerd era cirurgião-dentista, mestre em Odontologia. Foi coordenador de Saúde Bucal do município de Curitiba (PR). 
MBRO e nos Encontros Nacionais, além dos sanitaristas concursados do Ministério da Saúde, que já vinham integrando a DNSB e também participavam dos Enatespo.

A proposta do grupo técnico era a formulação de uma nova política para o país voltada para a implantação através das Secretarias Estaduais de Saúde, tendo em vista que o processo de municipalização da saúde no país ainda não havia se consolidado totalmente. (CARVALHO et al., 2009) Um dos assessores da DNSB à época ressaltou que a proposta se enquadrava melhor para os locais mais avançados na municipalização, a exemplo de Curitiba (PR).

No que se refere aos movimentos contra hegemônicos, o relatório final do VII Enatespo, realizado de 27 a 30 de agosto de 1990, destacava que reconhecia a DNSB como instância política normativa e não executiva necessária à formulação de diretrizes nacionais a serem adequadas às realidades locais.

O relatório, abordou, ainda, que a política nacional deveria ser definida e implementada a partir de um colegiado com representantes dos estados e municípios. A DNSB deveria também cumprir o papel de instância articuladora e facilitadora das ações descentralizadas bem como assessorar, informar e difundir a educação para a saúde bucal. (ENATESPO, 1990) Outra recomendação foi posicionar a PNSB, que deveria ser baseada na Odontologia integral, privilegiando a manutenção e a promoção da Saúde Bucal e buscando a redução e o controle das doenças bucais, junto às demais políticas de saúde e políticas socioeconômicas do governo, a fim de garantir sua efetivação e o repasse de verbas, consolidando a municipalização. (ENATESPO, 1990)

Soares (2014) estudou o surgimento da Aboprev e a consolidação do espaço da Odontologia Preventiva e Social (OPS) no Brasil..55

A autora apontou que a criação da Aboprev foi um marco para a criação deste espaço, que sofreu influência das publicações dos países escandinavos sobre a etiologia da doença periodontal e cárie. (SOARES, 2014) Dois dos assessores da DNSB eram o presidente e um dos diretores da Aboprev, conforme já citado, assim como o próprio Sérgio Weyne se tornou o diretor da Associação no mandato posterior ao de Rui Oppermann.

Ressalta-se a existência de uma Política de Saúde Bucal criada em 1989 e um Programa para sua operacionalização, o Precad, quando a nova gestão da DNSB

55 A Odontologia Preventiva e Social é um movimento considerado como contra hegemônico, relacionado com a Medicina Preventiva. Começa a ganhar força no Brasil na década de 1970 e influencia na criação dos Departamentos de Odontologia Preventiva e Social no Brasil. O movimento foi baseado nos estudos de cariologia e doença periodontal realizados nos países escandinavos. (SOARES, 2014) 
assumiu. Quais motivos levaram à descontinuidade da Política e Programa então vigentes? Quais as bases teóricas para a formulação da nova política?

As diferentes tomadas de posição teóricas influenciaram cursos diferentes das políticas de saúde bucal no Brasil. Enquanto o Precad era a expressão do conhecimento da Saúde Pública tradicional, difundido, principalmente, pela FSP/USP, baseada nas técnicas preventivas de massa, o novo grupo seguia os estudos escandinavos baseados em uma nova concepção do processo de lesão cariosa como multifatorial, oriunda de um processo de desmineralização e remineralizarão, fundamentados na microbiologia e bioquímica. Ademais, segundo os entrevistados, as propostas de fluoretação tópica, através da utilização de moldeiras proposta pelo Programa, tinha ação semelhante à escovação com dentifrício fluoretado, como a experiência dos Estados Unidos.

A concepção da cárie como devastadora e como um fenômeno sem controle ou de difícil solução, conforme analisado na década de 1980, era combatida pela Aboprev. Weyne defendia a cárie como uma doença multifatorial. ${ }^{55}$ Segundo o Entrevistado 9, o flúor teria grande importância em seu controle, mas não poderia ser encarado como "a solução para todos os problemas", pois não seria capaz de interferir em todos os fatores e acrescentou que "se for a solução de todos problemas o Rio de Janeiro por exemplo tem água fluoretada e praticamente todo mundo usa creme dental com flúor e tem atividade cariosa e lesão cariosa”.

Em publicação da Aboprev, Weyne (1999) apontou que a formação em Odontologia preconizava que o cirurgião-dentista deveria aguardar o aparecimento de danos na dentição para iniciar o chamado tratamento curativo. Esta prática acarretava o aparecimento de novas lesões, muitas vezes enquanto o profissional ainda desempenhava sua prática restauradora em outros dentes. O profissional que se deparava, rotineiramente, com situações como essas, substituía o material restaurador anterior por outros em cavidades mais extensas, o que acarretava maior perda de substância dental. Muitas vezes, o destino daquelas unidades dentárias resultava na extração, o que o autor chamou de círculo vicioso do paradigma cirúrgico-restaurador no qual a alternativa passava a ser a reabilitação através de próteses dentárias. Assim, o autor defendia que a atenção odontológica baseada exclusivamente nos procedimentos operatórios não seria capaz de controlar as doenças bucais nem de evitar a perda dental e condenaria o dentista a ser um "fiscal de demolição" dos dentes de seus pacientes.

No mesmo trabalho, Weyne (1999) criticou o critério de Tratamento Completado (TC) utilizado nos serviços públicos brasileiros para crianças e adolescentes, através do qual o usuário recebia "alta” do tratamento odontológico após o término 
do tratamento restaurador. O autor argumentou que as restaurações não tinham a capacidade miraculosa de controlar, por si próprias, as condições "intra e extrabucais que modulam a atividade cariosa”.

A prática previdenciária também reforçava o sistema incremental, através do TC, a exemplo das Ações Integradas em Saúde (AIS). (WERNECK, 1994) Na faixa etária de adultos, o número de extrações era de, aproximadamente, 35 milhões de dentes extraídos/ano por estimativa do Ministério da Saúde, sendo que este procedimento se encontrava dentre aqueles melhor remunerados pelo SUS até 1992. (WEYNE, 1999) Assim, apesar de um discurso voltado para a prevenção por correntes do campo científico, a prática reforçava o procedimento extração. Segundo o mesmo, a alternativa encontrada, na tentativa de reverter o quadro, foi reduzir o valor do procedimento na tabela de custeio do SUS. Um grande aliado do diretor da DNSB, no período, era Ricardo Akel, médico, que ocupava o cargo de secretário nacional de Assistência à Saúde e de presidente do Inamps. (CARVALHO et al., 2009; WEYNE, 1999)

Uma questão que mexia muito comigo é que eu fui ver as estatísticas do Ministério da Saúde e vi que o evento que era mais contemplado no atendimento era extração. Eu me lembro que eu fui conversar com o Secretário Nacional, depois com o Ministro e eu fiz uma frase assim: - Nós temos uma máquina de fazer desdentados no Ministério da Saúde e eu não quero ser o maquinista. Eu acho que a gente tem de alguma forma modificar isso, e uma forma que me ocorre agora é baixar o valor de extração que era o procedimento mais bem pago. [...] Eu pedi ao Secretário Nacional e eu confirmei o que eu suspeitava, então tinha lá o procedimento mais bem pago era extração, então a primeira proposta foi diminuir e foi aceito. ${ }^{56}$

O Programa Odontológico Escolar de Saúde (Proesa), que serviu de inspiração para a nova política da DNSB ${ }^{57}$ (CARVALHO et al., 2009), foi um programa desenvolvido na Secretaria Municipal de Saúde de Porto Alegre, em meados da década de 1980, liderado por Ruy Oppermann, que se baseava na definição de grupos prioritários de escolares a partir do risco biológico para a cárie dentária e buscava reduzir e controlar a cárie através da "fluorterapia intensiva". (CARVALHO et al., 2009)

Na publicação de 1999, Weyne afirmou que uma das propostas mais coerentes para começar a reduzir o "homicídio odontológico" e alterar a "filosofia do 
tratamento" se materializou com a mudança da tabela de financiamento do SIA/ SUS para procedimentos odontológicos e com a formulação da política dos procedimentos coletivos. Em entrevista Weyne diz que:

Não existem formas de as pessoas fazerem procedimentos preventivos por uma razão muito simples, porque eles não são pagos. Então vamos criar um conjunto de práticas que nós chamamos de procedimentos coletivos e que vai se incluir o pagamento por aplicação tópica de flúor no consultório, compra de creme dental com flúor, compra de escova. Eu falei com os ministros: - vocês têm vacina em medicina, nós não temos vacina em Odontologia e uma das coisas que não é vacina, mas que se aproxima um pouco é que as crianças e a população tenham acesso a escova de dente e creme dental. Fizemos um levantamento e a população era muito carente de escova e creme dental. Então [...] entrou uma portaria que se instituía os procedimentos coletivos, foi a primeira vez que isso apareceu e eles eram pagos e todas as pessoas que tivessem inscrição no atendimento do SUS fariam jus o recebimento de uma escova de $3 \mathrm{em} 3$ meses e um tubo de creme dental com flúor a cada mês ou 2 tubos a cada 3 meses [...] defendi meu caso, o Ministro não queria assinar, o Secretário não queria assinar, foram convencidos a assinar, eles assinaram a portaria está aí [...].

Assim, em 9 de outubro de 1991 foi publicada a Portaria $n^{\circ} 184$, assinada pelo secretário nacional, Ricardo Akel, que criou três tipos de procedimentos coletivos em saúde bucal. A Portaria, que anunciava entrar em vigência a partir de $1^{\circ}$ de janeiro de 1992, era justificada pela mudança do modelo de atenção odontológica no país e para a reversão da situação de saúde bucal no país assim como pela necessidade de compatibilizar o financiamento das ações com o novo modelo proposto. (BRASIL, 1991d)

A Tabela publicada na referida data tratava de procedimentos individuais e coletivos. O subgrupo dos procedimentos coletivos (PC) foi dividido em três componentes e cada um destes fixava um valor do programa por "cliente" por mês. O PC I era constituído pelo "conjunto de procedimentos de promoção e prevenção em saúde bucal, de baixa complexidade, dispensando equipamentos odontológicos, desenvolvidos integralmente em grupos populacionais previamente identificados" e fixava o valor de Cr\$520 (R $\$ 1,81)^{58}$ programa/cliente/mês, sendo com-

58 Valores convertidos de Cruzeiro para Real, com deflação pelo IPCA (IBCE), a partir de calculadora disponibilizada pelo Banco Central do Brasil. 
posto por exame epidemiológico, ${ }^{59}$ educação em saúde, ${ }^{60}$ bochechos fluorados ${ }^{61}$ e higiene bucal supervisionada. ${ }^{62}$ Este é o primeiro registro em política de cunho nacional da utilização da escovação supervisionada. Já a fluoretação tópica era utilizada desde o sistema incremental. O PC II consistia em todos os procedimentos do PC I acrescidos de exame clínico para diagnóstico, terapia intensiva com flúor no valor de Cr\$780 (R \$2,71) programa/cliente/mês. Já o PC III contemplava todos os procedimentos do PC I e do PC II acrescidos de remoção de cálculo e polimento dentário, escariação e selamento de cavidade com cimento provisório, aplicação de selantes, remoção de raízes residuais, aplicação de cariostático, correspondendo ao valor de $\mathrm{Cr} \$ 900(\mathrm{R} \$ 3,13)$.

Werneck (1994) aponta que os PC são uma iniciativa da gestão nacional para implementar procedimentos preventivos de abrangência coletiva, entretanto, estes também pressupõem atividades cirúrgicas básicas, como remoção de focos residuais e restaurações provisórias que fazem parte da adequação do meio bucal para outros tratamentos individuais.

O subgrupo dos procedimentos individuais iniciava sua descrição com o exame clínico e era composto por um elenco de ações em componentes denominados Odontologia Preventiva (I, II, III, IV e V); Dentística (I e II); Endodontia e Odontologia Cirúrgica (I e II).

No componente Odontologia Preventiva I constava apenas a Higiene Bucal Supervisionada; já na Odontologia Preventiva II, a aplicação tópica de flúor por indivíduo, selante e cariostático por dente, além de coleta de material para citologia esfoliativa. Os procedimentos de Periodontia como raspagem alisamento e polimento dentário, assim como curetagem subgengival, compunham a Odontologia Preventiva (OP) III e IV, respectivamente. Na OP V, constavam procedimentos de ortodontia e pediatria. Nos componentes de Dentística existiam restaurações de amálgama, resina e também a pino. As exodontias de dentes decíduos e permanentes assim como as múltiplas e de raízes residuais compuseram o bloco da Odonto-

59 Realizado anualmente para verificar as modificações no quadro epidemiológico das doenças bucais no grupo atendido. (BRASIL, 1991d)

60 Atividades educativas realizadas em periodicidade trimestral, enfatizando os cuidados com a saúde bucal.

61 Realizados semanalmente durante todo o ano com soluções de fluoreto de sódio a 0,2\%, sendo, no mínimo, 25 aplicações.

62 Evidenciação de placa bacteriana e escovação supervisionada com pasta fluoretada, realizadas, no mínimo, a cada três meses, ao longo do ano, fornecendo a cada participante uma escova de dentes e um tubo de pasta fluoretada de 90 ou 100 gramas, a cada três meses. (BRASIL, 1991d) 
logia cirúrgica. Já na Endodontia observa-se a possibilidade de pulpotomia e tratamento para dentes uni, bi ou trirradiculares, entretanto, não previa retratamentos.

Em 24 de dezembro do mesmo ano, foi publicada a Portaria $n^{\circ} 198$, que tornou sem efeito a Portaria $n^{0} 184$ que fora publicada anteriormente. A justificativa perpassou a adequação dos códigos aos procedimentos afins e o ajuste às especialidades de Cirurgia e Prótese bucomaxilofacial. O início da vigência é mantido para 1 de janeiro de 1992. Não existiram mudanças relativas aos Procedimentos Coletivos e quanto aos componentes de Odontologia Preventiva e Dentística dos subcomponentes Procedimentos Individuais quando comparados à Portaria anterior, entretanto, os valores foram reajustados para os PC e Procedimentos Individuais (PI). Os PC tiveram mudança em seus valores: PC I - Cr\$676,00 (R\$2,90); PC II Cr\$1.014,00 (R\$4.36) e PC III - Cr\$1.170,00 (R\$5.03). O percentual de aumento foi de $30 \%$ para todos os PC.

Foram acrescentados procedimentos de Estomatologia, Cirurgia Periodontal, Cirurgia bucomaxilofacial de nível ambulatorial e hospitalar e Prótese bucomaxilofacial, incluindo aquelas intraorais, faciais, complementares das radioterapias, além da manutenção periódica destas próteses. A anestesia geral em tratamento odontológico também foi incluída e a Odontologia Cirúrgica (I, II e III) passou a integrar o componente Endodontia. Ressalta-se que o valor das exodontias dos dentes decíduos (Cr\$1.512,00 - R\$6.50) e extrações simples de dentes permanentes eram próximos dos PC III.

Ao analisar o período de 1988 a 1991 quanto ao custeio dos procedimentos odontológicos de 1988 a 1989, pela Previdência, e dos anos 1990 e 1991, pelo Ministério da Saúde, observa-se uma mudança na distribuição dos valores na tabela de 1991. A extração de dentes decíduos se equiparou com as extrações simples sendo que, nos anos anteriores, seu valor era inferior àquele das extrações em dentes permanentes. $\mathrm{O}$ valor atribuído ao exame odontológico era praticamente o mesmo que se atribuía às extrações, entretanto, na tabela de 1991, há uma redução proporcional no valor deste procedimento. Há, também, uma redução da proporção entre os valores de aplicação tópica de flúor, entretanto, o valor do PC III correspondia a $77,4 \%$ do valor relacionado à extração.

A tabela sofreu ajustes quanto ao conteúdo, com a Portaria ${ }^{\circ} 298$, de 16 de junho de 1992, publicada no DOU em 19 de junho de 1992 (BRASIL, 1992d), que retirava o exame epidemiológico do PC I, enquadrando-o no PC II.

A nova tabela do Sistema de Informações Ambulatoriais do SUS contemplava ações educativas coletivas assim como a produção de ações odontológicas no nível individual, mas com uma indução para que o atendimento clínico também con- 
templasse as ações de prevenção (CARVALHO et al., 2009), além daquelas ações de recuperação e reabilitação que já constavam da tabela da Previdência Social e do Ministério da Saúde em 1990.

O grupo técnico assessor que conduzia a implantação da nova política pretendia desenvolver os PC em municípios pilotos e, após essa fase, capacitar dentistas de estados e municípios com os membros da Aboprev. Entretanto, a exoneração do ministro Alcenir Guerra por acusação de compras irregulares impediu o planejamento inicial. (CARVALHO et al., 2009)

A FIO, através de seu presidente Swendenberg Barbosa, em audiência com o presidente do Inamps, em 12 de maio de 1992, contestou a forma de pagamento por produtividade que vinha sendo adotada pelo Inamps. O fato seguia a lógica do setor privado, gerando concorrência entre os profissionais, além de possibilitar a corrupção. (AUDIÊNCIA..., 1992) O presidente da Federação também foi eleito pelas entidades odontológicas para compor o Conselho Nacional de Saúde na categoria profissionais. (FIO..., 1992a)

O MBRO se mostrava desarticulado e um dos seus últimos boletins, em 1990, conclamava participantes a ingressarem no Movimento, abordando que o seu papel até então tinha sido de catalisar, estimular e aglutinar ideias de renovação. O boletim também abordava a pauta de pessoal auxiliar. (BOLETIM INFORMATIVO NACIONAL DO MOVIMENTO BRASILEIRO DE RENOVAÇÃO, 1990)

O relatório final do VIII ENATESPO (1991) também repudiou o pagamento de serviços por produção, "imposto" pelo Ministério da Saúde/Inamps aos municípios e estados. Afirmava que "a pretensão tutelar do Ministério da Saúde é inaceitável”, exigia o repasse de verbas segundo critérios demográficos, criticava a exclusão de grupos não prioritários, como adultos e crianças de zero a três anos, e reiterava, ainda, a necessidade de integração das ações de saúde bucal nas práticas coletivas de saúde e o resgate da integralidade dessas práticas.

Em jornais de grande circulação, críticas gerais às condições de saúde bucal da população eram destacadas. Gilberto Alfredo Pucca Júnior, dentista, diretor do Centro de Referência em Saúde do Trabalhador e coordenador de Saúde Bucal do distrito de Sé da prefeitura municipal de São Paulo, publicou duas matérias, "A tragédia da saúde bucal no Brasil” e "A saúde bucal no Brasil”, ambas no jornal Folha de São Paulo, no ano de 1992, que tratavam de financiamento e da necessidade de superação da dicotomia cura x prevenção, destacando os resultados de estudos da OMS segundo os quais, aos 20 anos, os brasileiros já possuíam 19 dentes cariados. 
Tabela 2 - Valor dos procedimentos odontológicos e razão entre estes e as extrações dentárias de 1988 a 1991, Brasil**

\begin{tabular}{cccccccccccc}
\hline & $\begin{array}{c}\text { Extração } \\
\text { de dente } \\
\text { permanente }\end{array}$ & \multicolumn{2}{c}{$\begin{array}{c}\text { Extração de dente } \\
\text { decíduo }\end{array}$} & \multicolumn{2}{c}{$\begin{array}{c}\text { Exame } \\
\text { odontológico }\end{array}$} & $\begin{array}{c}\text { Aplicação tópica } \\
\text { de flúor }\end{array}$ & PC III \\
\hline Ano & Valor & Valor & Razão* & Valor & Razão* & Valor & Razão* & Valor & Razão* \\
\hline 1991 & $\mathrm{R} \$ 6,50$ & $\mathrm{R} \$ 6,50$ & 1,00 & $\mathrm{R} \$ 2,90$ & 0,45 & $\mathrm{R} \$ 3,12$ & 0,48 & $\mathrm{R} \$ 5,03$ & 0,77 \\
1990 & $\mathrm{R} \$ 15,24$ & $\mathrm{R} \$ 12,57$ & 0,82 & $\mathrm{R} \$ 14,37$ & 0,94 & $\mathrm{R} \$ 9,74$ & 0,64 & $\mathrm{NSA}^{* *}$ & $\mathrm{NSA}^{* *}$ \\
1989 & $\mathrm{R} \$ 13,20$ & $\mathrm{R} \$ 10,89$ & 0,82 & $\mathrm{R} \$ 12,45$ & 0,94 & $\mathrm{R} \$ 1,28$ & 0,64 & $\mathrm{NSA}^{* *}$ & $\mathrm{NSA}^{* *}$ \\
1988 & $\mathrm{R} \$ 73,57$ & $\mathrm{R} \$ 60,77$ & 0,83 & $\mathrm{R} \$ 70,21$ & 0,95 & $\mathrm{R} \$ 47,33$ & 0,64 & $\mathrm{NSA}^{* *}$ & $\mathrm{NSA}^{* *}$ \\
\hline
\end{tabular}

* A razão foi calculada em função do valor de extração de dentes permanentes com alveoloplastia nos períodos de 1988 a 1991 e extração simples de dentes permanentes em 1991, em função da mudança na nomenclatura dos procedimentos na tabela de custeio do SIA/SUS. Todas as moedas foram convertidas para Real com correção do IPCA - IBGE para fins de comparação.

** Não se aplica pois não existia o PC III nos anos anteriores a 1991.

Fonte: elaborado pela autora.

Werneck (1994) destacou a importância, através da indução federal, de um modelo assistencial com maior ênfase em trabalhos preventivos e fundamentados em base epidemiológica mais sólida. Outros autores, como Carvalho e colaboradores (2009), corroboram que houve um impulso para que as ações de prevenção e promoção da saúde alcançassem muitos municípios brasileiros tendo em vista o processo crescente de municipalização da saúde, além de ter contribuído para alterar o modelo de prática odontológica no setor público, direcionando-o para ações preventivas e de promoção da saúde.

Lemos (2002) estudou a expansão dos investimentos e a cobertura dos PC, tendo concluído que os estados que mais investiram foram Mato Grosso, Mato Grosso do Sul, Minas Gerais e Santa Catarina, sendo que o maior percentual médio de coberturas na população alvo ocorreu no Mato Grosso do Sul e em Santa Catarina. Ressaltou, ainda, a incompatibilidade do pagamento por ato em medidas coletivas, que não deveriam ser avaliadas em base individual, mas apontou grande importância dos Procedimentos nas estratégias públicas de combate à cárie dental com alocação de recursos consideráveis, apesar da baixa cobertura populacional em muitos estados e no Distrito Federal.

Werneck (1994) enfatizou que o maior efeito da nova política, em um Sistema de Saúde cujo modelo é definido pela tabela de custeio, foi permitir que os municípios organizassem seus programas de acordo com o que preconizam o PC I e o PC II, além de aumentar a arrecadação mensal, o que poderia ser investido em equipa- 
mentos, instrumentais, recursos humanos, dentre outros. O autor exemplifica com o caso de Belo Horizonte (MG) onde a implantação do PC II no Programa de Saúde Bucal passou a representar $30 \%$ de toda a arrecadação da Secretaria Municipal de Saúde, em 1993.

Críticas foram realizadas quanto ao termo "procedimento coletivo", tendo em vista que o PC não representava apenas um procedimento. (CARVALHO et al., 2009) era um termo do campo médico destinado a ações clínicas de cunho individual. O PC é constituído por um conjunto de ações e o fato de igualar atos distintos criava dificuldades nos registros para mensuração e avaliação do trabalho prestado, o que comprometia a própria credibilidade do registro. (CARVALHO et al., 2009) Ademais, militantes do MBRO também faziam críticas à nova política tendo em vista que existia um foco no fenômeno biológico em detrimento dos determinantes sociais e das mudanças no processo de trabalho, entretanto, não foram detalhadas alternativas para uma nova formulação da política.

Mas naquela altura, em 1991 [...] era um programa odontológico que caiu no gosto de todo mundo, não tem conflito, não tem determinante social, não tem que resolver nada com relação ao processo de trabalho, ratifica teorias odontológicas placogênicas [relacionadas à placa bacteriana], bacteriana e de açúcar, essa coisa toda de açúcar e tal que dá a ideia de que a sociedade tem que ser orientada, ensinada, monitorada, vigiada tal, porque ela édeletéria, ela tem hábitos deletérios, né? Ela come açúcar feito uma besta, ela não se escova e vamos que vamos. Então, como era um programa odontológico, um programa controlista, ideologicamente entra, coincide com o ponto de vista dos departamentos de odontologia social, todos, com a odontopediatria, e está mantido até hoje porque ele está no gosto da molecada. É uma coisa que todo mundo gosta. [...]. (Entrevistado 3, dentista, professor universitário) 